\title{
Bypass grafts protect diabetic patients better than angioplasty
}

Scott Gottlieb, New York

People with diabetes who have coronary artery disease fare much better after bypass surgery than after balloon angioplasty, according to a new report.

A second report, based on the same study as the first report, found that diabetic patients taking medication who have had coronary bypass surgery are more likely to survive a subsequent heart attack than are diabetic patients who have undergone angioplasty instead.

The results given in both reports come from the bypass angioplasty revascularization investigation (BARI), a 13-year study of patients randomly assigned to undergo either bypass surgery or angioplasty.

Researchers had previously reported that the survival rate 5 years after treatment was similar for both types of treatment. But among the 353 diabetic patients in the study, researchers had found that those who had had angioplasty were much less likely still to be alive than those who had bypass surgery.

In both of the reports, the lead author of the BARI trial, Katherine Detre of the University of Pittsburgh in Pennsylvania, followed the participants for an additional 2 years to see if these differences continued.

In the first report, researchers followed about 2000 patients for an additional 2 years and found that the type of intervention made no difference to survival except in the case of diabetic patients. Diabetic patients did worse in both respects - mortality and heart attacks.

For diabetic patients, the 7-year survival rate was $76.4 \%$ in the bypass group and about $55.7 \%$ in the angioplasty group; among patients who did not have diabetes, the survival rates were $86.4 \%$ and $86.8 \%$, respectively ( $\mathrm{Am}$ Coll Cardiol 35:11221129,1130-1132).

Detre said that survival rates also varied among diabetic patients who had undergone angioplasty, depending on how their diabetes was treated. Compared with diabetic patients who took oral diabetes drugs, those who used insulin injections fared worse after angioplasty. People taking insulin might have had more severe diabetes, but she and her colleagues were not able to verify this.

Because most of the people in the BARI trial were not diabetic and many advances in the treatment of heart disease have occurred since the study was conducted, researchers plan a new study that will include only people with diabetes.

The conclusions in Detre's second study were also based on an assessment of patients enrolled in the BARI trial and included both diabetic and non-diabetic patients. Among diabetic patients who had heart attacks after the start of the study, Detre found that mortality 5 years after the heart attack was $17 \%$ for those who had undergone bypass surgery compared with $80 \%$ for those who had undergone angioplasty ( $N$ Engl J Med 2000; 342:989-997).

Both types of coronary revascularization resulted in an immediate increase in the amount of heart muscle receiving blood flow. But investigators noted that after 1 year, the vessels of the patients who had undergone bypass surgery remained open to a greater degree, thus protecting them somewhat from the sequelae of a second heart attack.

The findings published in both reports were based on data collected before newer innovations in coronary angioplasty. The researchers noted that newer research shows that stents keep blood vessels open longer.

In an accompanying editorial to the second report, Steven Haffner of the University of Texas in San Antonio said that stents could improve survival among diabetic people who had heart attacks. Detre's group is planning a study that will test that theory.

\section{ANY QUESTIONS?}

Do you have a clinical question you'd like to see answered? If so, here's your chance to get a curbside consult from our expert team, which includes many of the top clinicians in the West.

\section{ANY ANSWERS?}

Maybe you have strong views about something you read in this issue-something we got wrong perhaps? Or do you have further clinical experience you'd like to share? Perhaps you have suggestions for new topics you'd like to see us address from an evidence-based perspective.

Whatever questions, comments, or other contributions you have, we'd like to receive them. We realize that it's experience like yours that makes the journal come alive. Please send your questions, ideas, or comments to us by email: wjm@ewjm.com. 